\title{
Rethinking the gold standard of correction for paravalvular leak: Why correct when you can prevent?
}

\author{
David W. Yaffee, MD, Mathew R. Williams, MD, and Eugene A. Grossi, MD
} \author{
Disclosures: Authors have nothing to disclose with regard to commercial support. \\ 2016. \\ (E-mail: eugene.grossi@nyumc.org). \\ J Thorac Cardiovasc Surg 2016;152:e103-4 \\ $0022-5223 / \$ 36.00$ \\ Copyright (C 2016 by The American Association for Thoracic Surgery \\ http://dx.doi.org/10.1016/j.jtcvs.2016.07.057
}

From the Department of Cardiothoracic Surgery, New York University School of Medicine, New York, NY.

Received for publication July 27, 2016; accepted for publication July 29, 2016; available ahead of print Sept 20,

Address for reprints: Eugene A. Grossi, MD, NYU Medical Center, 530 First Ave, Suite 4K, New York, NY 10016

Clinically significant paravalvular leak (PVL), although uncommon, has been associated with mediocre long-term survival after both aortic and mitral valve replacement. In the past decade, open surgical correction of PVL has been supplanted at many centers by transcatheter device closure as first-line therapy. Although data comparing the 2 techniques are limited, long-term recurrence and survival remain suboptimal in retrospective series, suggesting that there may be better management options.

In this issue of the Journal, Vekstein and colleagues ${ }^{1}$ report a case of open implantation of vascular plugs to seat a mitral prosthesis in a heavily calcified annulus during aortic and mitral valve replacements in a patient with previous mediastinal radiation. After implantation, the mitral prosthesis was left with a sizeable paravalvular gap in an area of residual confluent annular calcium, which likely would have resulted in significant PVL. Two vascular plugs were inserted under direct vision to seat the valve and fill the gap. Postoperative echocardiogram showed good valvular function with no PVL. Although this technique has been reported for the correction of PVL, ${ }^{2}$ this is the first report of prophylactic use to prevent PVL. But is this better than our current management strategies?

In the largest series of surgical PVL repair to date, Bouhout and colleagues ${ }^{3}$ looked at 190 patients with a mean follow-up of more than 5 years and found a 30-day mortality of 7\% (8\% for mitral valve replacement, $3 \%$ for aortic valve replacement, and $14 \%$ for both), with an $8 \%$ reoperation rate for bleeding and a $2 \%$ permanent stroke rate. PVL recurrence rates were not insignificant at 3\%, 14\%, and $32 \%$ at 1,5 , and 10 years, respectively, with survival of $85 \%, 73 \%$, and $56 \%$, respectively. All patients had less than $2+$ residual PVL.

In a systematic review of transcatheter treatment of PVL, Cruz-Gonzalez and colleagues ${ }^{4}$ reported a technical success rate (no significant residual PVL) of $77 \%$ to $86 \%$ and a clinical success rate (reduction of $\mathrm{New}$ York Heart Association functional class $\geq 1$ ) of $67 \%$ to

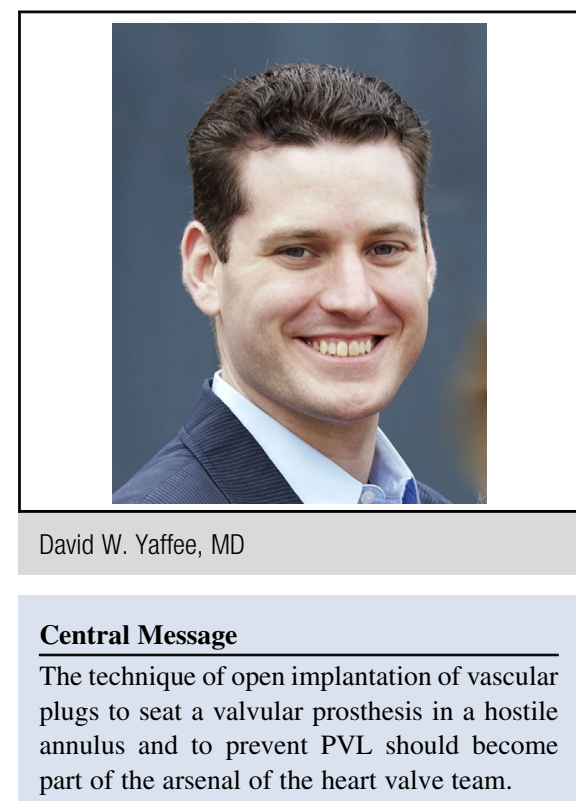

See Article page e101.

$77 \%$, with a hospital mortality of $2.2 \%$ and a $2.6 \%$ stroke rate. Other complications included vascular injury $(2 \%)$, cardiac perforation $(4 \%)$, device embolization $(4 \%)$, and valvular dysfunction requiring reoperation $(0.9 \%)$.

The case report by Vekstein and colleagues ${ }^{1}$ raises an interesting question: Can we achieve better results preventing PVL than responding to it? Although the benefits of open vascular plug implantation during the incident procedure would theoretically include greater accuracy and success of implantation, avoidance of perioperative hemodynamic derangements associated with postoperative PVL, and avoidance of the risks of subsequent interventions, the hybrid procedure may require significantly longer cardiopulmonary bypass, crossclamp, and total operative times. In addition, the risk of PVL would need to be identified during valve implantation and likely would not be helpful for prevention of late PVL, making its use limited to a highly selected group of patients, such as the one described in the report.

Although unlikely to revolutionize the management of PVL, the technique of open implantation of vascular plugs to seat a valvular prosthesis in a hostile annulus and to prevent PVL should become part of the arsenal of the heart valve team. 


\section{References}

1. Vekstein AM, Idrees J, Kapadia S, Johnston DR. Open vascular plug placement to complete mitral valve seating in radiation heart disease: a case report. J Thorac Cardiovasc Surg. 2016;152:e101-2.

2. Kulik A, Labinaz M, Beauchesne LM, Nicholson D, Bedard P. Hybrid repair of mitral paravalvular leak: open surgical placement of a percutaneous occluder device. J Thorac Cardiovasc Surg. 2006;132:1469-70.
3. Bouhout I, Mazine A, Ghoneim A, Millan X, El-Hamamsy I, Pellerin M, et al. Long-term results after surgical treatment of paravalvular leak in the aortic and mitral position. J Thorac Cardiovasc Surg. 2016;151: 1260-6.e1.

4. Cruz-Gonzalez I, Rama-Merchan JC, Calvert PA, Rodriguez-Collado J, Barreiro-Perez M, Martin-Moreiras J, et al. Percutaneous closure of paravalvular leaks: a systematic review. J Interv Cardiol. 2016;29:382-92. 